\title{
CORE DYNAMICS ANALYSIS FOR REACTIVITY INSERTION AND LOSS OF COOLANT FLOW TESTS USING THE HTTR
}

\author{
Kuniyoshi TAKAMATSU, Shigeaki NAKAGAWA and Tetsuaki TAKEDA \\ Japan Atomic Energy Agency \\ takamatsu.kuniyoshi@jaea.go.jp, nakagawa.shigeaki@jaea.go.jp and takeda.tetsuaki@jaea.go.jp
}

\section{INTRODUCTION}

This paper describes the validation results for the newly developed code, which was named ACCORD (Takamatsu, et al., 2006), using the experimental results of the reactivity insertion test as well as the loss of coolant flow tests by tripping one or two out of three gas circulators.

\section{ANALYTICAL RESULTS}

We used a conventional method, namely, a one-dimensional flow channel model and reactor kinetics model with a single temperature coefficient, taking into account the temperature changes in the core. However, a slight difference between the analytical and experimental results was observed. Therefore, we have modified this code to use a model with four parallel channels and twenty temperature coefficients in the core. Fig.1 shows the analytical results using the four flow channels and the twenty temperature coefficients in comparison with those of using the one flow channel and a single temperature coefficient.

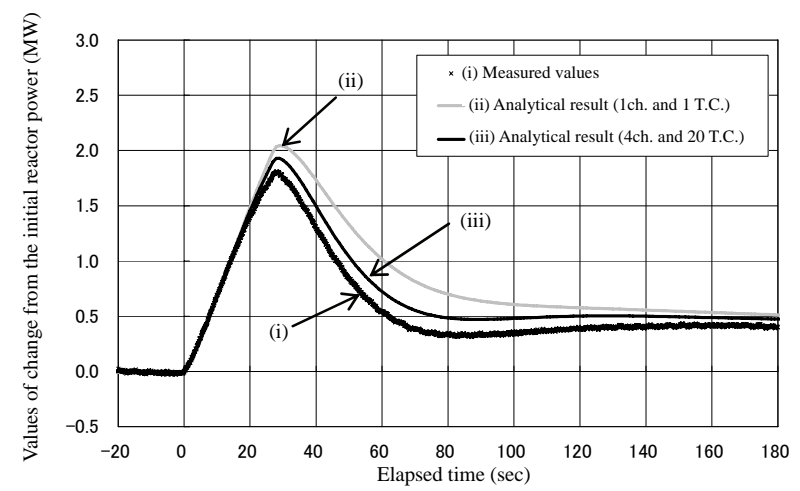

Fig. 1 Analytical results at the reactor power of 15MW and the CR withdrawal of $40 \mathrm{~mm}$ at low velocity

The peak power values of the analytical results are lager than those of the measured values, and these stable values stabilize to become equal after $100 \mathrm{sec}$. The validity of the point reactor kinetics approximation is verified from these tests. The analytical results using the four flow channels and the twenty temperature coefficients can demonstrate the transients of the reactor power better than those using the one flow channel and the single temperature coefficient.

The magnitude relation of the reactivities between the single temperature coefficient and the region temperature coefficients is given by equation (1); this is based on the condition that the change in temperature is small, about $14^{\circ} \mathrm{C}$ during the tests.

$$
\begin{aligned}
& \rho_{\text {single }}-\rho_{\text {multi }} \\
& =\sum_{i=1}^{N} \alpha_{i} \times \frac{\sum_{i=1}^{N} \Delta T_{i}}{N}-\sum_{i=1}^{N}\left(\alpha_{i} \times \Delta T_{i}\right) \\
& =-\frac{1}{N} \times \sum_{\substack{i=1, j=1 \\
i<j}}^{N}\left(\alpha_{i}-\alpha_{j}\right) \times\left(\Delta T_{i}-\Delta T_{j}\right)
\end{aligned}
$$

If the convex curves of the region temperature coefficients $\alpha_{i}$ and the rise in the region temperature $\Delta T_{i}$, are similar, the reactivity of the region temperature coefficients, $\rho_{\text {multi }}$, is always larger than that of a single temperature coefficient, $\rho_{\text {single }}$. In other words, $\left(\alpha_{i}-\alpha_{j}\right)$ and $\left(\Delta T_{i}-\Delta T_{j}\right)$ have the same sign, $\rho_{\text {multi }}$ is always larger than $\rho_{\text {single }}$

If the convexity curves of $\alpha_{i}$ and $\Delta T_{i}$ are not similar, $\rho_{\text {multi }}$ approaches $\rho_{\text {single }}$.

\section{CONCLUSIONS}

The reactivity insertion test is performed on the HTTR by withdrawing a pair of the control rods; based on this test, many important values for a HTGR's design and a safety review for the future have been determined. Moreover, in this report, a new analytical model is suggested and it is considered that the point reactor kinetics can be applied for reactor safety and accident analysis. Finally, the pre-analytical result of the loss of coolant flow test by tripping all gas circulators is also discussed. The reactor power decreases to decay heat level from the maximum reactor power of $30 \mathrm{MW}$ due to the negative reactivity feedback effect of the core. Although the reactor power becomes critical again about five hours later, the peak power value is merely $2 \mathrm{MW}$. It was confirmed that by using the developed code, it is possible to not only analyze the reactor core dynamics but also simulate the core dynamics during the abnormal events postulated in the HTGR safety analysis.

\section{REFERENCES}

Takamatsu, K., et al., 2006, J. Nucl. Sci. and Technol. (JP), Vol. 5, No.1, pp 45-56. 


\title{
CORE DYNAMICS ANALYSIS FOR REACTIVITY INSERTION AND LOSS OF COOLANT FLOW TESTS USING THE HTTR
}

\author{
Kuniyoshi TAKAMATSU, Shigeaki NAKAGAWA and Tetsuaki TAKEDA \\ HTGR Performance \& Safety Demonstration Group, Nuclear Applied Heat \\ Technology Division, \\ Nuclear Science and Engineering Directorate, Japan Atomic Energy Agency \\ 4002 Narita-cho Oarai-machi, Higashiibaraki-gun, Ibaraki-ken, 311-1393, JAPAN \\ Phone:+81 (29) 266 7665, Fax: +81 (29) 266 7486, \\ e-mail: takamatsu.kuniyoshi@jaea.go.jp
}

Keywords : HTTR, HTGR, Safety demonstration test, reactor kinetics, reactivity feedback effect

\begin{abstract}
The High Temperature engineering Test Reactor (HTTR) is a graphite-moderated and a gas-cooled reactor with a thermal power of $30 \mathrm{MW}$ and a reactor outlet coolant temperature of $950{ }^{\circ} \mathrm{C}$ (SAITO, 1994). Safety demonstration tests using the HTTR are in progress to verify its inherent safety features and improve the safety technology and design methodology for High-Temperature Gas-cooled Reactors (HTGRs) (TACHIBANA 2002) (NAKAGAWA 2004). The reactivity insertion test is one of the safety demonstration tests for the HTTR. This test simulates the rapid increase in the reactor power by withdrawing the control rod without operating the reactor power control system. In addition, the loss of coolant flow tests has been conducted to simulate the rapid decrease in the reactor power by tripping one, two or all out of three gas circulators. The experimental results have revealed the inherent safety features of HTGRs, such as the negative reactivity feedback effect. The numerical analysis code, which was named ACCORD (TAKAMATSU 2006), was developed to analyze the reactor dynamics including the flow behavior in the HTTR core. We used a conventional method, namely, a one-dimensional flow channel model and reactor kinetics model with a single temperature coefficient, taking into account the temperature changes in the core. However, a slight difference between the analytical and experimental results was observed. Therefore, we have modified this code to use a model with four parallel channels and twenty temperature coefficients in the core. Furthermore, we added another analytical model of the core for calculating the heat conduction between
\end{abstract}

the fuel channels and the core in the case of the loss of coolant flow tests. This paper describes the validation results for the newly developed code using the experimental results of the reactivity insertion test as well as the loss of coolant flow tests by tripping one or two out of three gas circulators. Finally, the pre-analytical result of the loss of coolant flow test by tripping all gas circulators is also discussed. The reactor power decreases to decay heat level from the maximum reactor power of $30 \mathrm{MW}$ due to the negative reactivity feedback effect of the core. Although the reactor power becomes critical again about five hours later, the peak power value is merely 2 MW. It was confirmed that by using the developed code, it is possible to not only analyze the reactor core dynamics but also simulate the core dynamics during the abnormal events postulated in the HTGR safety analysis.

\section{INTRODUCTION}

A high temperature engineering test reactor (HTTR) was built in the Oarai Research \& Development Center of the Japan Atomic Energy Agency (JAEA) to establish and enhance technologies for high temperature gas cooled reactors (HTGRs). The HTTR is the first gas-cooled reactor in JAPAN. A rise-to-power test was performed on the HTTR from March 31st to May 1st in 2004 as a phase five test with power up to $30 \mathrm{MW}$ in the high temperature test operation mode (FUJIKAWA, 2002) (NAKAGAWA 2004). It was confirmed that the thermal reactor power and the reactor outlet coolant temperature reached $30 \mathrm{MW}$ and $950^{\circ} \mathrm{C}$, respectively, on April 19th in the single operation mode by using only a primary pressurized water cooler (PPWC) 
(FUJIKAWA 2004) (TAKAMATSU 2004). The parallel loaded operation mode using an intermediate heat exchanger (IHX) and the PPWC, was performed from June 2nd. Subsequently, JAEA obtained a certificate for the pre-operation test on June 24th from the Ministry of Education, Culture, Sports, Science and Technology (MEXT) after all the pre-operation tests were successfully performed in the high temperature test operation mode. The reactor outlet coolant temperature of $950^{\circ} \mathrm{C}$ was achieved for the first time in the world. Thus, it is possible to achieve highly efficient power generation with a high temperature gas turbine and a production of hydrogen from water with a high-temperature. The present study is entrusted from the Ministry of Education, Culture, Sports, Science and Technology (MEXT) of Japan in FY2004.

\section{OUTLINE OF THE HTTR}

The core is composed of fuel assemblies, control rod (CR) guide blocks, and permanent reflector blocks that are circumferentially stacked. A perpendicular stacked row is referred to as a column, and the core consists of 61 columns. The core is divided into the fuel region including the fuel assemblies and the permanent reflector region surrounding the outside of the fuel region. The CR guide blocks are installed in both the regions.

Helium gas, the primary coolant, flows from the outer path of the high temperature concentric pipe to the core, and rises to cool the pressure vessel. After being inverted in the upper part of the reactor pressure vessel (RPV), the coolant is heated to a maximum of $950^{\circ} \mathrm{C}$ in the core. The coolant flows then from the inner path of the high temperature concentric pipe to the pressure vessel outside.

The fuel assembly is the so-called pin-in-block type composed of fuel rods and a hexagonal graphite block. The fuel compact comprises coated fuel particles (CFPs) consisting of a microsphere of low enriched UO2 with a TRISO (tri-isotropic) coating. The CFPs are incorporated into the fuel compacts with a graphite matrix. A fuel rod composed of fuel compacts and a graphite sleeve, is contained within the vertical hole of a graphite block. The HTTR has 954 flow channels in the core.

\section{REACTIVITY INSERTION TEST BY WITHDRAWING A CONTROL ROD}

The reactivity insertion tests performed without operating the reactor power control system, demonstrates a rapid increase in the reactor power caused by a rupture of the stand pipe. The simulation performed by withdrawing a pair of the control rods at the center does not cause a severe accident due to the inherent safety features, namely, the negative reactivity feedback effect of the core and the slow temperature transient in HTGRs. The peak power value, reduction in power speed, etc., obtained during the reactivity insertion test will be utilized for the development and validation of analytical models, reactivity coefficients, temperature coefficients, etc.

\subsection{Test procedure}

In the safety demonstration test using the HTTR, there are some operational restrictions with regard to safety. In the initial condition of the safety demonstration test, the reactor power and the reactor outlet coolant temperature must be below $80 \%$ (24MW) and $850^{\circ} \mathrm{C}$, respectively. In addition, during the tests, the reactor power, reactor inlet and outlet coolant temperatures, pressure, etc., will be maintained under the normal operation conditions. To appropriately set the plant parameters during the tests, the HTTR system is equipped with an operation-mode selector.

The operation mode is selected after confirming the initial conditions. In this test, the pair of the control rods at the center is withdrawn and the neutron flux, reactor inlet and outlet coolant temperatures, primary circuit flow rate, pressure, etc., are measured. After the test, the reactor power is adjusted to the initial value and the operation mode is then turned off.

\subsection{Test results}

Figs.1, 2 and 3 show the test results at the reactor power of 9MW, 15MW and 18MW, respectively. The vertical axis represents the deviation from the initial value of the reactor power.

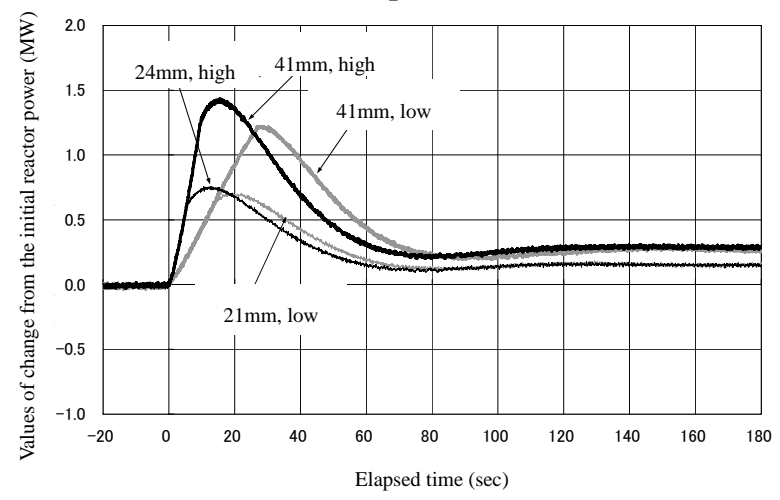

Fig.1 Test results at the reactor power of 9MW

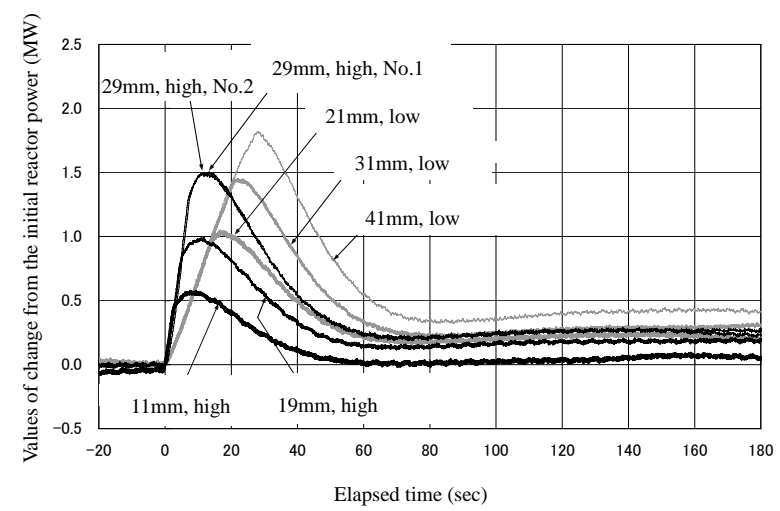


Fig.2 Test results at the reactor power of 15MW

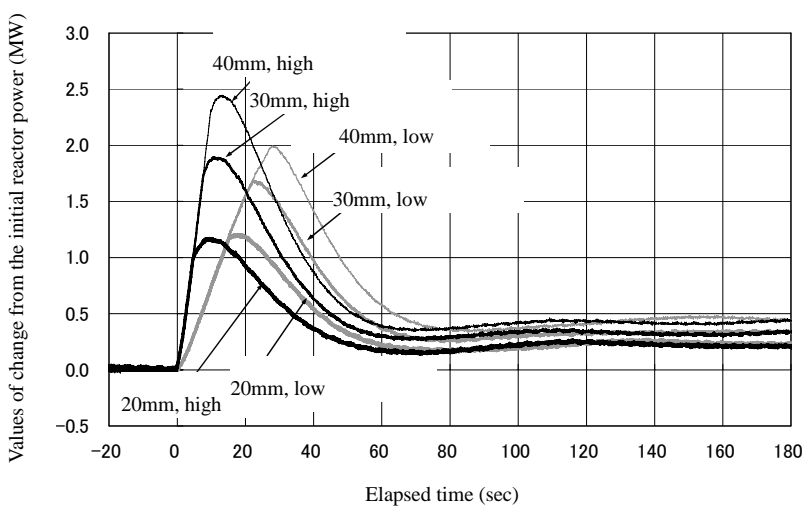

Fig.3 Test results at the reactor power of 18MW

There are large differences in the peak power values between the withdrawal of the control rod at low velocity (about $1 \mathrm{~mm} / \mathrm{sec}$ ) and high velocity (about $5 \mathrm{~mm} / \mathrm{sec}$ ). The peak power values at the low velocity are lower because the negative reactivity feedback effect restrains the increasing reactor power as listed in Table 1 . For all the cases, the reactor power becomes stable after withdrawal.

Table 1 Fuel and moderator temperature coefficients

\begin{tabular}{|c|c|c|}
\hline $\begin{array}{c}\text { Reactor } \\
\text { Power }\end{array}$ & $\begin{array}{c}\text { Fuel temperature } \\
\text { coefficient } \\
\left(\Delta \mathrm{k} / \mathrm{k} /{ }^{\circ} \mathrm{C}\right)\end{array}$ & $\begin{array}{c}\text { Moderator temperature } \\
\text { coefficient } \\
\left(\Delta \mathrm{k} / \mathrm{k} /{ }^{\circ} \mathrm{C}\right)\end{array}$ \\
\hline $9 \mathrm{MW}$ & $-5.0 \times 10^{-5}$ & $-5.3 \times 10^{-5}$ \\
\hline $15 \mathrm{MW}$ & $-4.5 \times 10^{-5}$ & $-3.1 \times 10^{-5}$ \\
\hline $18 \mathrm{MW}$ & $-4.0 \times 10^{-5}$ & $-2.8 \times 10^{-5}$ \\
\hline
\end{tabular}

9MW: average fuel temperature $600^{\circ} \mathrm{C}$, average moderator temperature $556^{\circ} \mathrm{C}$

15MW: average fuel temperature $794^{\circ} \mathrm{C}$, average moderator temperature $716^{\circ} \mathrm{C}$

18MW: average fuel temperature $888^{\circ} \mathrm{C}$, average moderator temperature $804^{\circ} \mathrm{C}$

\section{LOSS OF COOLANT FLOW TESTS BY TRIPPING ONE, TWO OR ALL OUT OF THREE GAS CIRCULATORS}

The loss of coolant flow tests performed without operating the reactor power control system demonstrate a rapid decrease in the reactor power caused by coolant flow reduction in the core. The simulation that involved the tripping of one, two or all out of three gas circulators did not cause a severe accident; this is due to the inherent safety features, namely, the negative reactivity feedback effect of the core and the slow temperature transient in HTGRs.

\subsection{Test procedure}

In this test, one, two or all out of three gas circulators are tripped and the neutron flux, reactor inlet and outlet coolant temperatures, primary circuit flow rate, pressure, etc., are measured. After the test, the reactor power becomes zero by manual reactor shutdown.

\section{REACTOR KINETICS}

5.1 Outline of reactor kinetics and method of analysis

The reactor kinetics and heat transfer in the core are important phenomena to be considered in the analysis of the reactivity insertion tests; therefore, the numerical analysis code - ACCORD- was developed to analyze the reactor dynamics including the flow behavior in the core. The analytical method for heat transfer and reactor kinetics uses a two-dimensional model and a flow channol as shown in Fig.4.

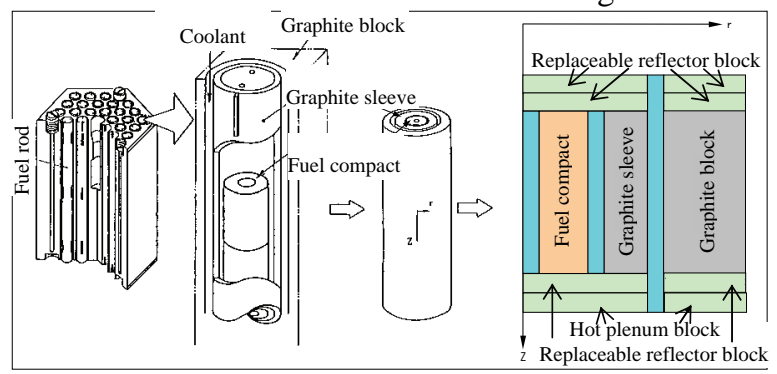

Fig.4 Analytical model of the ACCORD code

The total reactivity is the sum of the inserted, Doppler, moderator and xenon reactivities. The reactor power is calculated using the transient of total reactivity. For the point reactor kinetics model, a change in the power density distribution of the tests is not considered.

The neutronic characteristics, namely, the inserted reactivity and temperature coefficients, are needed for the reactor kinetics analysis; therefore, the inserted reactivity using the MVP code based on the Monte Carlo theory (NAGAYA, 2005) and the temperature coefficient using the MVP code and the CITATION code based on the diffusion theory (FOWLER, 1971), are calculated. The MVP code can be accurately used with analytical models for the fuel and moderator region of the HTTR. This calculation, however, is time consuming and does not yield the analytical results quickly. On the other hand, the calculation with the CITAION code is less time consuming. The CITATION code is very convenient to obtain many temperature coefficients referred to as region temperature coefficients in this report. JENDL-3.2 is used as the nuclear data library.

The use of one fuel temperature coefficient and one moderator temperature coefficient for the analysis of reactor kinetics is a conventional method. A reactivity of a single temperature coefficient is defined in equation (1).

$\rho_{\text {single }}=\alpha_{\text {single }} \times \Delta T_{\text {av }}$ 
The fuel assemblies containing the different degrees of enriched uranium at the HTTR, are set up in the core as listed in Table 2, to decrease the maximum fuel temperature. In particular, the four fuel assemblies are set up radially from the inside to the outside $-\mathrm{F} 1$ to F4 - as listed in Table 2, and the five fuel assemblies are set up axially from the top to the bottom -1 to $5-$ as listed in Table 2 . Considering this setup of the fuel assemblies, the core can be divided into four regions radially and five regions axially, twenty regions for calculating the region temperature coefficients as listed in Table 2.

Table 2 Setup of the fuel assemblies containing the different degrees of enriched uranium (wt\%)

\begin{tabular}{|c|c|c|c|c|}
\hline & $\begin{array}{c}\text { F1 } \\
\text { (Inside) }\end{array}$ & F2 & F3 & $\begin{array}{c}\text { F4 } \\
\text { (Outside) }\end{array}$ \\
\hline 1 (Top) & 6.7 & 7.9 & 9.4 & 9.9 \\
\hline 2 & 5.2 & 6.3 & 7.2 & 7.9 \\
\hline 3 & 4.3 & 5.2 & 5.9 & 6.3 \\
\hline 4 & 3.4 & 3.9 & 4.3 & 4.8 \\
\hline 5 (Bottom) & 3.4 & 3.9 & 4.3 & 4.8 \\
\hline
\end{tabular}

Firstly, the temperature distribution in the core solved by another thermal hydraulics analysis code is used for the temperature distributions in the regions. Secondly, the temperatures in each region are changed one by one in calculating the region temperature coefficients. Thus, the region temperature coefficients consider the temperature changes in each region. Finally, the region temperature coefficients are defined in equation (2).

$\rho_{\text {multi }}=\sum_{i=1}^{N}\left(\alpha_{i} \times \Delta T_{i}\right)$

If the neutron flux and neutron importance in the core do not change during the test, the single temperature coefficient becomes equivalent to the sum of the region temperature coefficients, as defined in equation (3). On the other hand, the rise in the average temperature is defined in equation (4).

$$
\begin{aligned}
\alpha_{\text {single }} & =\sum_{i=1}^{N} \alpha_{i} \\
\Delta T_{\mathrm{av}} & =\frac{\sum_{i=1}^{N} \Delta T_{i}}{N}
\end{aligned}
$$

The conventional model for heat transfer analysis uses one flow channel representing the 954 flow channels in the core, as shown in Fig.4. However, this analytical model does not consider the power density distributions radially and the temperature distributions axially based on the coolant flow rate distributions in the core. On the other hand, four flow channels in the core as listed in Table 2, can use these power density distributions and the coolant flow rates.

During the rated power operation carried out at a reactor power of $30 \mathrm{MW}$, the reactor inlet coolant temperature is $395^{\circ} \mathrm{C}$, while the reactor outlet coolant temperature is $950^{\circ} \mathrm{C}$; thus, the temperature difference between the inlet and the outlet coolant temperature is about $550^{\circ} \mathrm{C}$. Due to this, the axial temperature gradient of the coolant in the core is high.

Furthermore, we added another analytical model of the core for calculating the heat conduction between the fuel channels and the core in the case of the loss of coolant flow tests. The analytical method for heat transfer and reactor kinetics employs a two-dimensional core model as shown in Fig.5. The fuel channels are coupled for the data transfer, such as the component temperature and power distribution. The code can simulate the transients of the reactor power and the temperature in the core.

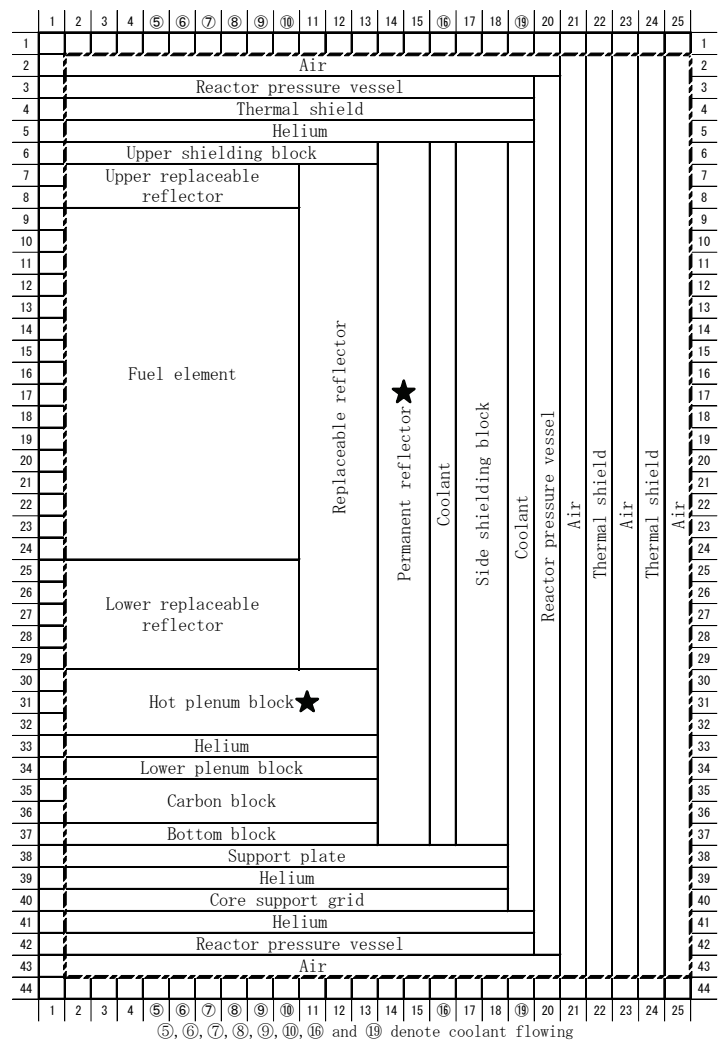

Fig. 5 Analytical model of the core of the HTTR $\star$ : measuring points

\subsection{Analytical conditions}

The analytical conditions are as follows: Some values containing statistical errors are calculated using the MVP code and the CITATION code 
because these values cannot be directly measured from the HTTR:

(1) The initial reactor power is calculated using the measured neutron flux.

(2) The value corresponding to the control rod withdrawal is calculated based on the position of the controls rods

(3) The velocity of the control rod withdrawal is calculated based on the position of the control rods

(4) The inserted reactivity calculated using the MVP code ranges from $1.4 \times 10-4 \Delta \mathrm{k} / \mathrm{k}$ to $4.8 \times 10-4 \Delta \mathrm{k} / \mathrm{k}$ with a statistical error of $\pm 10 \%$ (about $2 \sigma$ ).

(5) The fuel temperature coefficient is calculated using the MVP code and the CITATION code. The sum of the region temperature coefficients equals to a single temperature coefficient. The statistical error is $\pm 10 \%$ (about $2 \sigma$ ).

(6) The moderator temperature coefficient is calculated using the MVP code and the CITATION code. The sum of region temperature coefficients equals to a single temperature coefficient. The statistical error is $\pm 15 \%$ (about $2 \sigma$ ). It is verified that the fuel and moderator temperatures do not change significantly during the test; therefore, these changes do not affect the fuel temperature coefficients and the moderator temperature coefficients because the maximum region temperature rise is about $14{ }^{\circ} \mathrm{C}$ as stated in chapter 6.3 .

(7) The effective delayed neutron rate is calculated using the CITATION code and the DELIGHT code (SHINDO, 1990), which provide the group constants for the fuel assemblies and graphite blocks. The ENDF/B-IV is used as the nuclear data library. The effective delayed neutron rate is $0.70 \%$ for a burnup of 0 day, $0.61 \%$ of $9 \mathrm{MW}$ (reactor power) and $0.58 \%$ of $30 \mathrm{MW}$ for a burnup of 330 days. The effective delayed neutron rate for the burnup of 0 day does not depend on the reactor power. The burnups in this report are 138 days for $9 \mathrm{MW} ; 160$ days, $15 \mathrm{MW}$; and 181 days, 18 MW. Since, the difference in these burnups between $9 \mathrm{MW}$ and $18 \mathrm{MW}$ is 43 days, which is low, the effective delayed neutron rate is assumed as $0.65 \%$ in this report.

(8) The prompt neutron lifetime is calculated using the abovementioned method for determining the effective delayed neutron rate. This value does not depend on the burnup and the prompt neutron lifetime value used in this report is $9.4 \times 10^{-4} \mathrm{sec}$. Furthermore, this value does not affect the analytical results because the inputted reactivity is small.

\section{ANALYTICAL RESULTS}

6.1 Reactor transient in reactivity insertion test

Fig.6 shows the analytical results using the four flow channels and the twenty temperature coefficients in comparison with those of using the one flow channel and a single temperature coefficient. The peak power values of the analytical results are lager than those of the measured values, and these stable values stabilize to become equal after $100 \mathrm{sec}$. The validity of the point reactor kinetics approximation is verified from these tests. The analytical results using the four flow channels and the twenty temperature coefficients can demonstrate the transients of the reactor power better than those using the one flow channel and the single temperature coefficient.

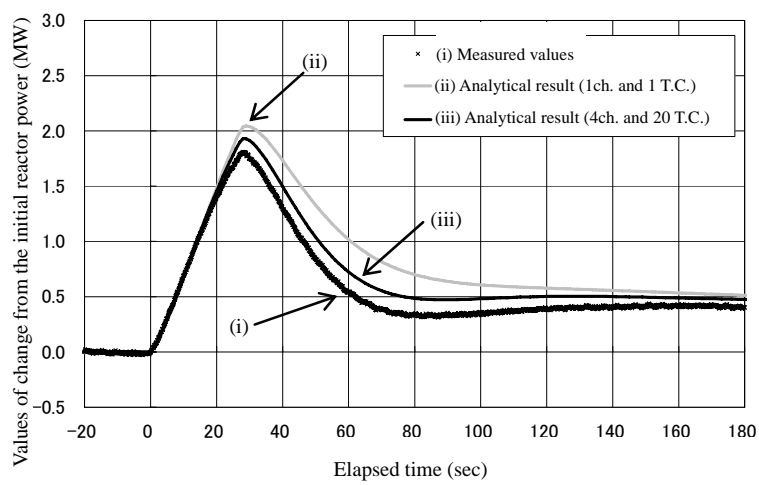

Fig.6 Analytical results at the reactor power of $15 \mathrm{MW}$ and the CR withdrawal of $40 \mathrm{~mm}$ at low velocity

\subsection{C/E of the peak power values}

The maximum $\mathrm{C} / \mathrm{E}$, which represents calculated values dividing by experimental ones of the peak power, is 1.15 (15\%) using one flow channel and a single temperature coefficient at the reactor power of $9 \mathrm{MW}$ and a control rod withdrawal value of $40 \mathrm{~mm}$ at low velocity. On the other hand, the minimum $\mathrm{C} / \mathrm{E}$ of the peak power value is 1.07 (7\%) with four flow channels and twenty temperature coefficients at a reactor power of 15MW and a control rod withdrawal value of $40 \mathrm{~mm}$ at low velocity as shown in Fig.6.

\subsection{Region temperature rise}

Fig.7 shows the rise in region temperature at a reactor power of 15MW and a control rod withdrawal of $40 \mathrm{~mm}$ at low velocity. The fuel assemblies are set up radially from the inside to the outside of the core - F1 to F4 - and axially from the top to the bottom -1 to $5-$ as listed in Table 2. These figures show the rise in region temperature from the top to the bottom axially. The temperatures from F1 to F4 overlap. The maximum region temperature rise is about $14{ }^{\circ} \mathrm{C}$. The temperature distribution after 30 sec clearly exhibits a convex curve. On the other hand, the temperature distribution after $180 \mathrm{sec}$ does not exhibit a convex curve, and the temperature of the top is lower than that of the bottom due to the forced-convection cooling. 


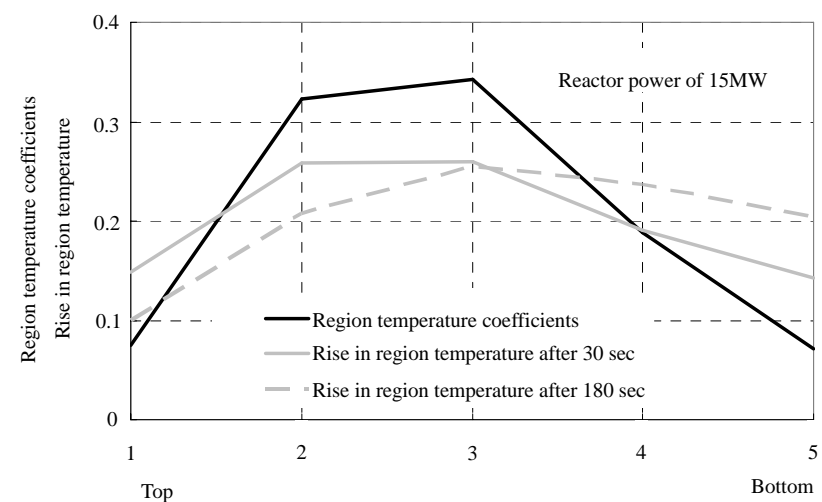

Fig.7 Normalized axial convex curves of the region temperature coefficients and the rises in region temperature

\subsection{Formulation of the magnitude relation of the reactivities}

The magnitude relation of the reactivities between the single temperature coefficient and the region temperature coefficients is given by equation (5); this is based on the condition that the change in temperature is small, about $14^{\circ} \mathrm{C}$ during the tests.

$\rho_{\text {single }}-\rho_{\text {multi }}$

$=\sum_{i=1}^{N} \alpha_{i} \times \frac{\sum_{i=1}^{N} \Delta T_{i}}{N}-\sum_{i=1}^{N}\left(\alpha_{i} \times \Delta T_{i}\right)$

$=-\frac{1}{N} \times \sum_{\substack{i=1, j=1 \\ i<j}}^{N}\left(\alpha_{i}-\alpha_{j}\right) \times\left(\Delta T_{i}-\Delta T_{j}\right)$

The normalized axial convex curves of the region temperature coefficients $\alpha_{i}$ and the rises in region temperature $\Delta T_{i}$ after $30 \mathrm{sec}$ and $180 \mathrm{sec}$ are shown in Fig.7 If the convex curve of the region temperature coefficients $\alpha_{i}$ (Fig.7) is similar to that of the rise in region temperature $\Delta T_{i}$ after $30 \mathrm{sec}$ (Fig.7), the reactivity of the region temperature coefficients $\rho_{\text {multi }}$ at this time (Fig.8) is always larger than that of the single temperature coefficient $\rho_{\text {single }}$. In other words, if $\left(\alpha_{i}-\alpha_{j}\right)$ and $\left(\Delta T_{i}-\Delta T_{j}\right)$ have the same signs as shown in Fig.7, $\rho_{\text {multi }}$ after $30 \mathrm{sec}$, is always larger than $\rho_{\text {single }}$ as shown in Fig.8. On the other hand, if the convex curve of $\alpha_{i}$ (Fig.7) is not similar to that of $\Delta T_{i}$ after $180 \mathrm{sec}$ (Fig.7), $\rho_{\text {multi }}$ at the time, approaches $\rho_{\text {single }}$ as shown in Fig.8. Consequently, the convex curve of the rise in region temperature after $30 \mathrm{sec}$ is more similar to that of the region temperature coefficients than after 180 sec.

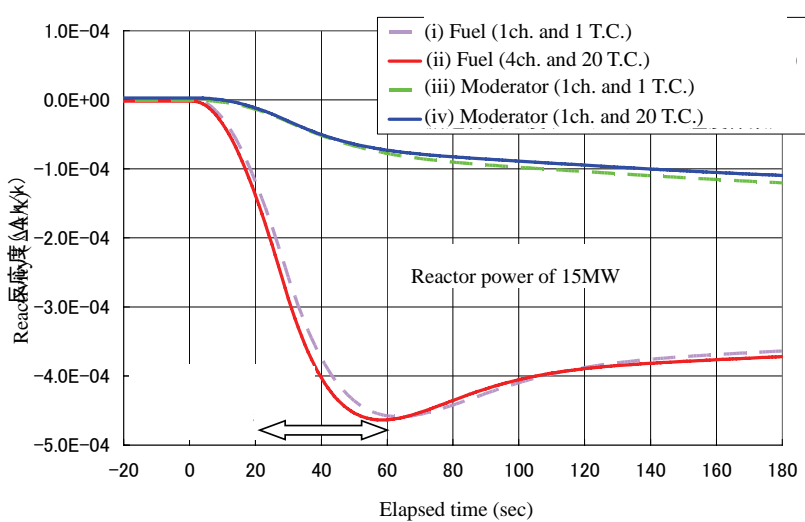

Fig.8 Reactivities using one channel and one temperature coefficient in comparison with those of 4 channels and 20 temperature coefficients at the reactor power of $15 \mathrm{MW}$

\subsection{Reactor transient in one or two gas circulators trip test}

From the experimental results of the one or two gas circulators trip test, it was verified that the reactor power decreases due to the negative reactivity feedback effect of the core even if the reactor shutdown system is not operational, and that the temperature distribution in the core changes slowly. The analytical conditions and results of the test are as follows:

(1) The test conducted at $9 \mathrm{MW}$ in which one or two gas circulators out of three was tripped.

(2) The primary coolant flow rate was reduced and finally controlled to about $15 \mathrm{t} / \mathrm{h}$ or $30 \mathrm{t} / \mathrm{h}$ from the initial flow rate of about $45 \mathrm{t} / \mathrm{h}$; this was possible because the one or two remaining gas circulators maintained their initial flow rate with the primary coolant flow control system.

(4) The measured values of the coolant flow rate and reactor inlet coolant temperature are entered into the code and then compared with those obtained at the measuring points.

(5) Fig.9 and Fig.11 show a comparison between the values obtained from the measuring points shown in Fig.5 and the analytical results. The two green arrows denote the directions of the temperature transient. Values from the analytical results that are equal to the measured values fall on the solid red line; on the other hand, the broken red lines indicate values of the analytical results that are equal to the measured values $\pm 20^{\circ} \mathrm{C}$. The analytical results of the steady state and the unsteady state temperature distribution agree with the measured values within $20^{\circ} \mathrm{C}$, that is, $10 \%$ of the measured temperature. This temperature difference shows good agreement during the entire transient because $20^{\circ} \mathrm{C}$ divided by the measured value is about $10 \%$. Furthermore, as shown in Fig.5, no thermocouple was used in the fuel element due to the very high temperature. Moreover, the standard error of the thermocouple and measuring system is 
generally $10 \%$ for the range of $0^{\circ} \mathrm{C}$ to $1000^{\circ} \mathrm{C}$. These temperature differences show good agreement during the entire transient.

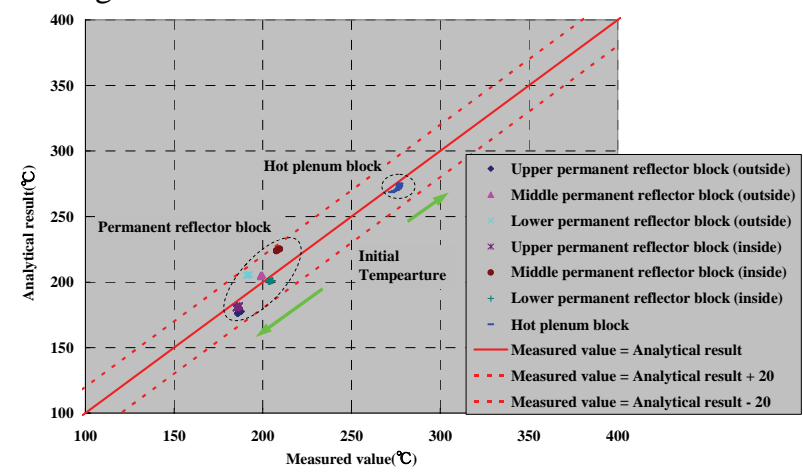

Fig.9 Transient temperature distribution for one-gas-circulator trip test

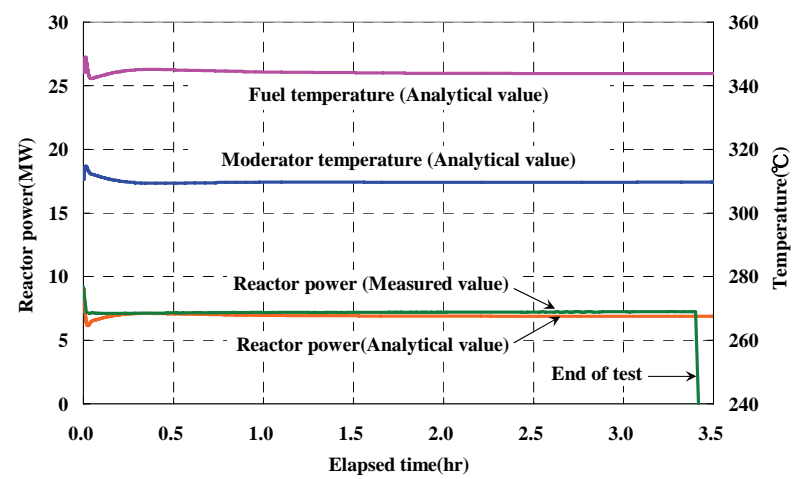

Fig.10 Transient reactor power and temperature distribution for one-gas-circulator trip test

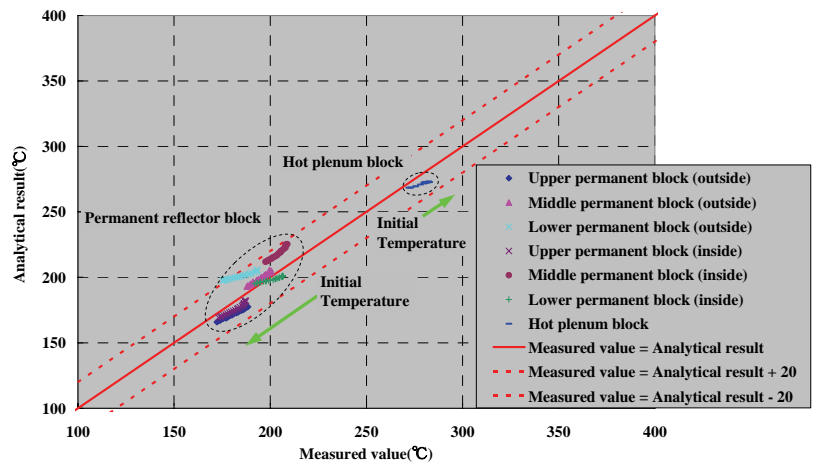

Fig. 11 Transient temperature distribution for two-gas-circulator trip test

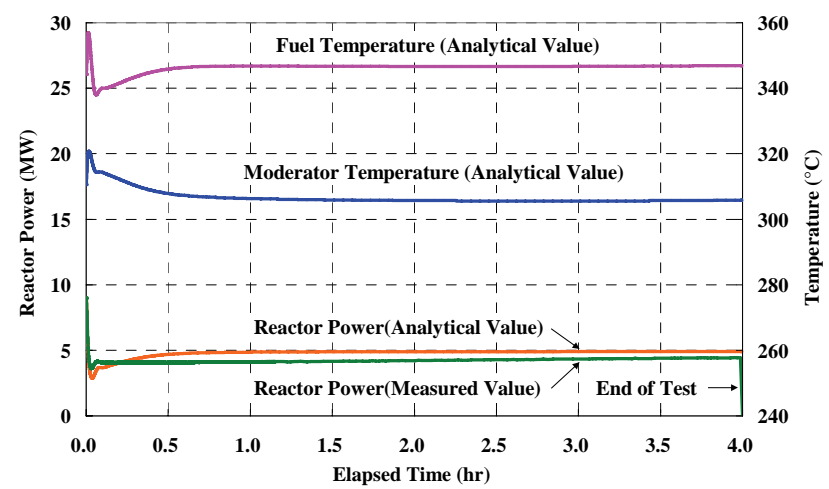

Fig. 12 Transient rector power and temperature distribution in two-gas-circulator trip test

(6) The transient reactor power is shown in Fig.10 and Fig.12. The reactor power decreased to about 7.2 MW or 4.2MW from the initial reactor power of 9 MW due to the negative reactivity feedback effect of the core. The analytical result of transient reactor power shows good agreement during the test, and they are identical to the measured values. Therefore, it was confirmed that the code was able to simulate the reactor transients in the test in which one gas circulator out of three was tripped.

\subsection{Reactor transient in all gas circulators trip} test

From the pre-analytical results of the all gas circulators trip test, it will be verified that the reactor power decreases due to the negative reactivity feedback effect of the core even if the reactor shutdown system is not operational, and that the temperature distribution in the core changes slowly. The pre-analytical conditions and results of the test are as follows:

(1) The test conducted at $30 \mathrm{MW}$ in which all gas circulators was tripped.

(2) The primary coolant flow rate was reduced to 0 $\mathrm{t} / \mathrm{h}$ from the initial flow rate of about $45 \mathrm{t} / \mathrm{h}$.

(3) Figs.13 and 14 show that the reactor power decreases to decay heat level from the maximum reactor power of $30 \mathrm{MW}$ due to the negative reactivity feedback effect of the core. Although the reactor power becomes critical again about five hours later, the peak power value is merely $2 \mathrm{MW}$. Therefore, it was confirmed that the code was able to simulate the reactor transients in the test in which all gas circulators out of three was tripped.

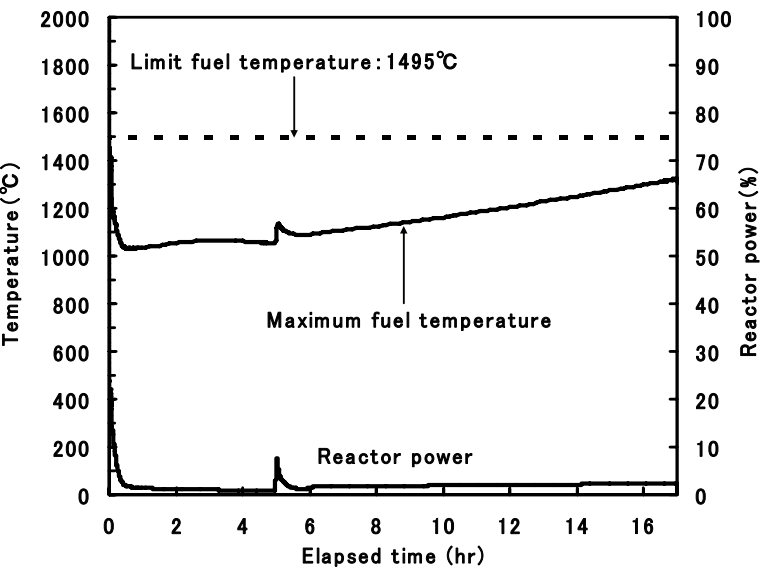

Fig. 13 pre-analytical results (1) of the all gas circulators trip test 


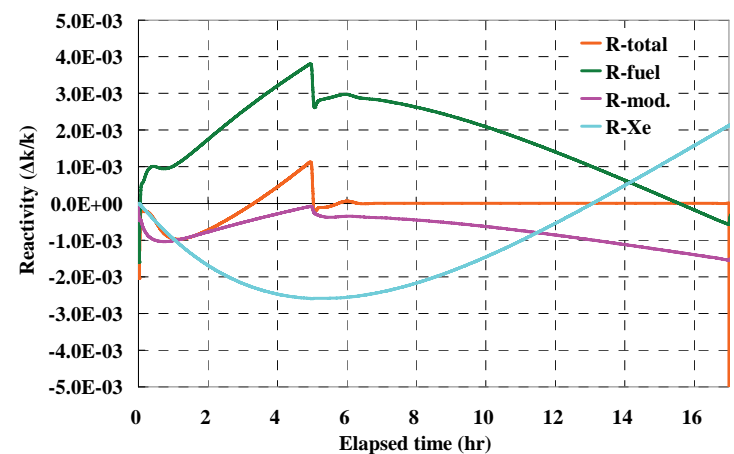

Fig. 14 pre-analytical results (2) of the all gas circulators trip test

\section{CONCLUSIONS}

The reactivity insertion test is performed on the HTTR by withdrawing a pair of the control rods; based on this test, many important values for a HTGR's design and a safety review for the future have been determined. Moreover, in this report, a new analytical model is suggested and it is considered that the point reactor kinetics can be applied for reactor safety and accident analysis. The conclusions are as follows:

(1) The maximum $\mathrm{C} / \mathrm{E}$ of the peak power values is 1.15 (15\%) by using the one flow channel and the single temperature coefficient. There are differences between the peak power values of the analytical results and the measured values until these values become stable. On the other hand, the minimum $\mathrm{C} / \mathrm{E}$ of the peak power values is 1.07 (7\%) by using the four flow channels and the twenty temperature coefficients. In this case, the abovementioned differences are less.

(2) If the convex curves of the region temperature coefficients $\alpha_{i}$ and the rise in the region temperature $\Delta T_{i}$, are similar, the reactivity of the region temperature coefficients, $\rho_{\text {multi }}$, is always larger than that of a single temperature coefficient, $\rho_{\text {single }}$. In other words, $\left(\alpha_{i}-\alpha_{j}\right)$ and $\left(\Delta T_{i}-\Delta T_{j}\right)$ have the same sign, $\rho_{\text {multi }}$ is always larger than $\rho_{\text {single }} \cdot$

(3) If the convexity curves of $\alpha_{i}$ and $\Delta T_{i}$ are not similar, $\rho_{\text {multi }}$ approaches $\rho_{\text {single }}$.

(4) To analyze the reactor kinetics of HTGRs, the region temperature coefficients taking into account the distribution of the fuel assemblies using different degrees of enriched uranium should be considered. Further, the rise in region temperature taking into account the temperature variation in the direction of the coolant flow should be considered. In this report, the formulation of the effect on the region temperature coefficients and the rise in region temperature is proposed.

(5) Considering the difference between the analytical results and the measured values, an appropriate safety margin can be set by using the new analytical model proposed in this paper. Finally, considerable cost reduction can be achieved while constructing HTGRs in the future.

\section{ACKNOWLEDGMENTS}

The authors would like to express their appreciation to Mr. Yoshihiro Komori, Mr. Toshio Nakazawa, Mr. Kozo Kawasaki, Mr. Tatsuo Iyoku and Mr. Toshihiko Mizushima of JAEA for their useful comments and advice. The authors also would like to express their appreciation to $\mathrm{Mr}$. Minoru Goto and Mr. Naoki Nojiri of JAEA for their efforts to evaluate nuclear parameters such as a control rod withdrawal, temperature coefficients of reactivity, etc.

\section{REFERENCES}

SAITO, S., et al., 1994, "Design of High Temperature Engineering Test Reactor”, JAERI 1332.

TACHIBANA, Y., et al., 2002, “Safety Demonstration Test Plan of the High Temperature Engineering Test Reactor (HTTR)," JAERI-Tech 2002-059.

NAKAGAWA, S., et al., 2004, “Safety Demonstration Tests using High Temperature Engineering Test Reactor,” Nucl. Eng. Des., Vol.233, pp301-308.

TAKAMATSU, K., et al., 2006, "Improvement of Core Dynamics Analysis of Control Rod Withdrawal Test in HTGR,” J. Nucl. Sci. and Technol. (JP) Vol.5, No.1, pp45-56.

FUJIKAWA, S., et al., 2002, "Rise-to-Power Test of the HTTR (High Temperature Engineering Test Reactor,” J. Nucl. Sci. Technol. (JP), Vol.1, No.4, pp361-372.

NAKAGAWA, S., et al., 2004, "Performance Test of HTTR,” Nucl. Eng. Des., Vol.233, pp291-300.

FUJIKAWA, S., et al., 2004, “Achievement of Reactor-outlet Coolant Temperature of $950^{\circ} \mathrm{C}$ in HTTR,” J. Nucl. Sci. Technol. Vol.41, No.12, pp1245-1254.

TAKAMATSU, K., et al., 2004, "Rise-to-Power Test in High Temperature Engineering Test Reactor in the High Temperature Test Operation Mode," JAERI-Tech 2004-063.

NAGAYA, Y., et al., 2005, "MVP/GMVP II: General Purpose Monte Carlo Codes for Neutron and Photon Transport Calculations based on Continuous Energy and Multigroup Methods,” JAERI 1348.

FOWLER, T. B., et al., 1971, "I Nuclear Reactor Core Analysis Code, CITATION,” ORNL-TM-2496.

SHINDO, K., et al., 1990, "DELIGHT-7; One Dimensional Fuel Cell Burnup Analysis Code for High Temperature Gas-cooled Reactors (HTGR)," JAERI-M 90-048. 